\title{
SWIRL NUMBER MEASUREMENTS USING INTAKE PORTS PRODUCED BY ADDITIVE
} MANUFACTURING

\author{
Martioli, G. F. ; Massarani, M. ${ }^{2}$ \\ ${ }^{1}$ Scania Latin America \\ ${ }^{2}$ Polytechnic School of Sao Paulo (EPUSP) - Mechanical Engineering \\ E-mails: gustavo.martioli@ scania.com, massarani@me.com
}

\begin{abstract}
The present work proposes to execute bench test swirl number measurements using a modular device and cylinder head intake ports from a diesel engine manufactured via additive manufacturing (AM). Swirl number measurements with intake ports produced by AM, bring the following advantages: Tests reproducibility, since having the geometric model (CAD) of tested models is enough to re-build the geometry analyzed in the bench test. Easy to measure the swirl number variances in consequence of potential manufacturing process deviations and time reduction to the development of new intake ports geometry. The research is experimental, one sample of the investigated cylinder head was sent to the Polytechnic School of Sao Paulo (EPUSP) laboratory, and the swirl number was measured and recorded for later results comparison with proposed method. This cylinder head sample was then sectioned and digitalized as to know to have the same internal geometry in the intake ports produced via AM. All tests were performed in the same rig and with the same control system aiming to reduce the external variables during data acquisition. When the swirl number results between the complete cylinder head and modular device using AM were compared, no statistically significant changes were found.
\end{abstract}

\section{INTRODUCTION}

According to the IEA (International Energy Agency), in 2014, the transport sector was responsible by $23 \%$ of dioxide carbon emissions (CO2) by combustion in the world [1]. The automotive industry challenge is to reduce the emissions in the atmosphere [2].

The emission gases are formed during the combustion process and the combustion process improvement is fundamental to reduce the fuel consumption and emissions [3]. Proper definition of the swirl number in Diesel cycle engines is important to keep the engine's emissions and consumption targets, according to the design specifications, because it influences in the fuel evaporation and also in the fuel-air mix [4].

"Swirl can be defined as organized rotation of the charge about the cylinder axis. Swirl is created by bringing the intake flow into cylinder with an initial angular momentum" [5].

Swirl influences within the engine cylinder air-fuel mixing and combustion process in diesel engines and also has impact on heat transfer [5-6]. 
Comprehension of swirl in the combustion process provides a better trade-off between exhaust emission gases (particulate matter, NOx, HC and $\mathrm{CO}$ ) and the fuel consumption [7].

In addition to the adequate swirl number definition during the project development phase, it's needed to take into consideration potential cylinder head manufacturing deviations. Despite of the huge number of publications about internal combustion engines, the process deviations influence into engine flow has been scarcely studied [8].

The four main problems that notably influence in the cylinder head ports intake flow in consequence of casting or machining process [9]:

- Inclination;

- Eccentricity;

- Swelling;

- Deformation;

This work aims to contribute with swirl number measurements using intake ports produced by AM. Using such approach is possible to measure the impacts of potential manufacturing process deviations since early development stages.

In order to validate the proposed method, a comparison between the results of intake ports produced via AM with a complete cylinder head is performed.

\section{ADDITIVE MANUFACTURING}

The ASTM F42 Technical Committee defines additive manufacturing (AM) as the "process of joining materials to make objects from three-dimensional (3D) model data, usually layer upon layer, as opposed to subtractive manufacturing methodologies" [10].

"The term AM describes additive fabrication processes in the broadest way that includes AM of prototypes (for design verification, form and fit checking), tools, patterns, and concept parts, as well as functional parts with required properties for direct industrial applications and services" [11].

Among the AM techniques, 3D printing was selected because there is no need of specialized or costly manufacturing equipment. Which is beneficial in terms of cost if compared with other available techniques [12-13].

Swirl number measurements with intake ports produced by AM, has the following characteristics:

- Tests reproducibility: since having the geometric model (CAD) of tested models is enough to re-build the geometry analyzed in the bench test.

- Easy to measure the swirl number variances in consequence of potential manufacturing process deviations: internal geometry of intake ports can be changed according to the intended process deviation and then tested into steady state cylinder flow. 
- Time reduction to the development of new intake ports geometry: few hours needed to produce and test a new sample of intake ports.

The main advantage of using AM for producing the intake ports is the agility, geometry control and variables involved in the functional tests. In approximately 24 hours is possible to produce and start testing a new pair of intake ports.

\section{IN-CYLINDER FLOW MEASUREMENTS}

In-cylinder flow rig is the equipment that proper defines the intake ports and valves swirl characteristics (at a fixed opening), being exhausted used by this purpose [5].

The intake airflow in steady state rig measurements is an important step in the engine development to comprehend the volumetric efficiency and flow properties and optimize it [14-15].

As show in Fig. 1 [16], a typical steady flow rig consists of a surge tank, valve lift adjustment, torque meter, flow measurement. In addition to data is needed a data acquisition system and a computer to process the data.

For this work, it was imposed a $250 \mathrm{mmH} 2 \mathrm{O}$ drop pressure to ensure a fully turbulent flow. In this paper, the AVL method [17-18], was used to evaluate the performance of intake port.

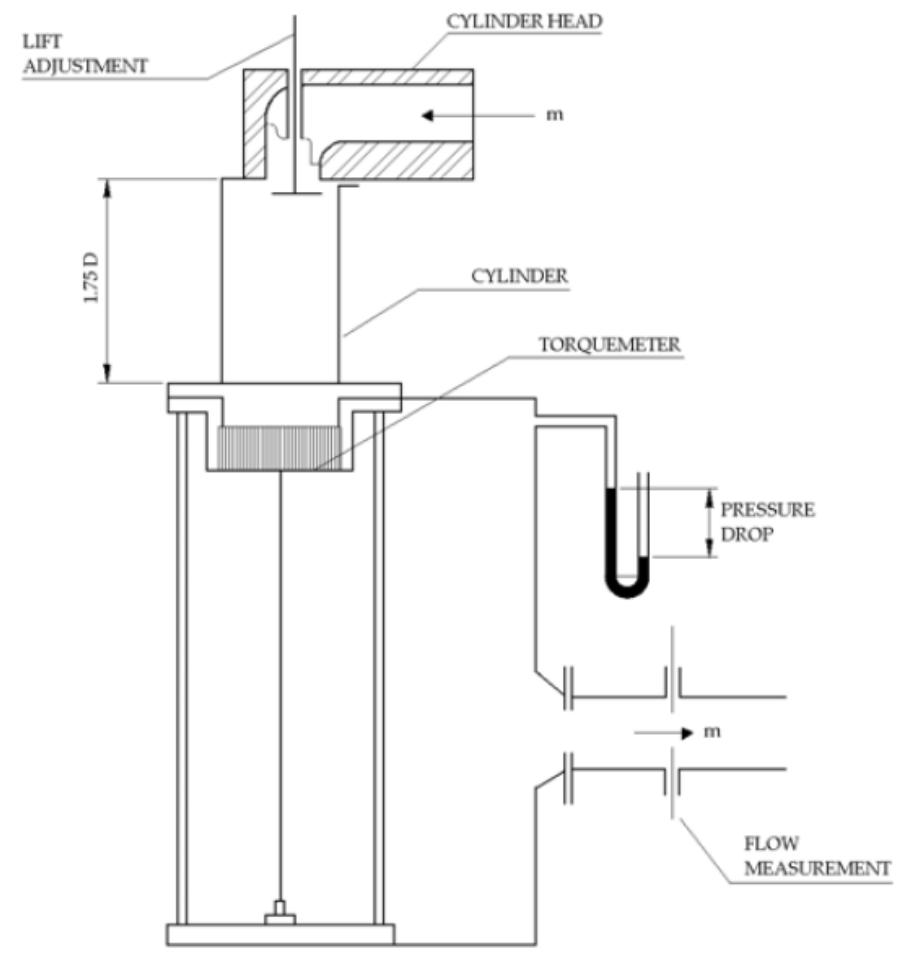

Figure 1 -Steady test flow rig [16] 
Although several parameter was acquired during the tests, only the swirl number will be presented in this paper, since the goal is to compare the results of a complete cylinder head vs. intake ports produced via AM (3D printing).

The swirl coefficient, $\left(C_{s}\right)$, is a ratio obtained from the angular momentum measured by the honeycomb at each valve lift, is defined as [17-18]:

$c_{s}=2 S \frac{M \rho}{q^{2}}$

Where $S$ is the engine stroke, $M$ is the torque at honeycomb (measured during the test), $\rho$ is the density of the air in the cylinder and $q$ is the mass flow rate (measured during the test).

The swirl number, $N_{s}$, the global swirl parameter during the entire intake process, can be defined as:

$N_{s}=\frac{1}{\pi} \int_{0}^{\pi} C_{s}\left(\frac{c(\alpha)}{c_{m}}\right)^{2} d \alpha$

Where $c(\alpha)$ is the instantaneous piston velocity (depending on the crankshaft angle $-\alpha$ ) and $c_{m}$ is the mean piston velocity.

Due to confidentiality restrictions, the cylinder head studied in this paper, that is used for Scania OEM diesel engines will be generic named as Model A.

\section{DESIGN}

Established requisites in the modular device design:

- Being able to reproduce the project design of Model A cylinder head, this is required to validate the proposed methodology with AM.

- Manipulation and intake ports changes for testing by only one person.

- Prepare the device for a new test set-up in less than 5 minutes.

- Integrate the flow straighter in the intake ports - flow straighter is represented in green at Fig. 2.

- Being able to reproduce the machining process in the intake ports.

- Simulate translation of $1 \mathrm{~mm}$ along the axis: $\mathrm{X}, \mathrm{Y}$ and $\mathrm{Z}$.

- Simulate rotations of 1.5 degrees around the axis: $\mathrm{X}, \mathrm{Y}$ and $\mathrm{Z}$.

The rotational and translational requirements from the modular device aims at emulating the potential deviations resulting from cylinder head manufacturing process. 


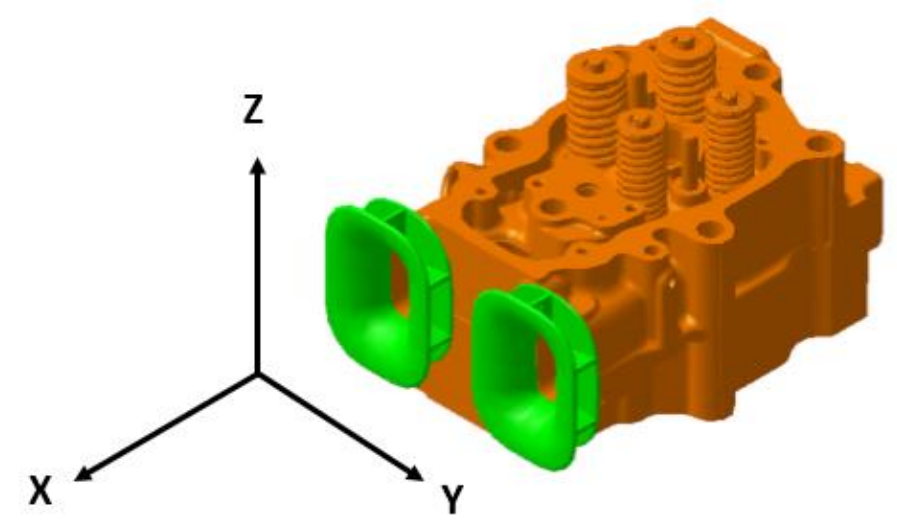

Figure 2 - Model A cylinder head with the flow straighter (green item) and axis orientation

As show in Fig. 2, the axis orientation used in this paper.

In the present work, 3D printed intake port were built with $4 \mathrm{~mm}$ thickness to keep a proper mechanical resistance to manipulate parts and reduce the amount of material used to produce each prototype port. After an investigation in the concept definition phase, it was confirmed that such thickness is enough to withstand all proposed motions.

Aiming optimize the modular device, it was designed one bracket for each port, in this way individual rotations would be possible without the need to produce a new prototype intake port. For each bracket is possible to have 3 different assembly positions:

- Neutral: intake port would keep the initial design coordinates

- 1.5 degrees positive: intake port would rotate 1.5 degrees clock wise in Z-axis.

- 1.5 degrees negative: intake port would rotate 1.5 degrees counter clock wise in Zaxis.

In case of the need to simulate process deviations in Z-axis, spacers can be used, increasing the opportunities to check manufacturing deviations without the need of producing new ports.

The exploded view of the modular device design used to validate the proposed method can be seem at Fig. 3. 


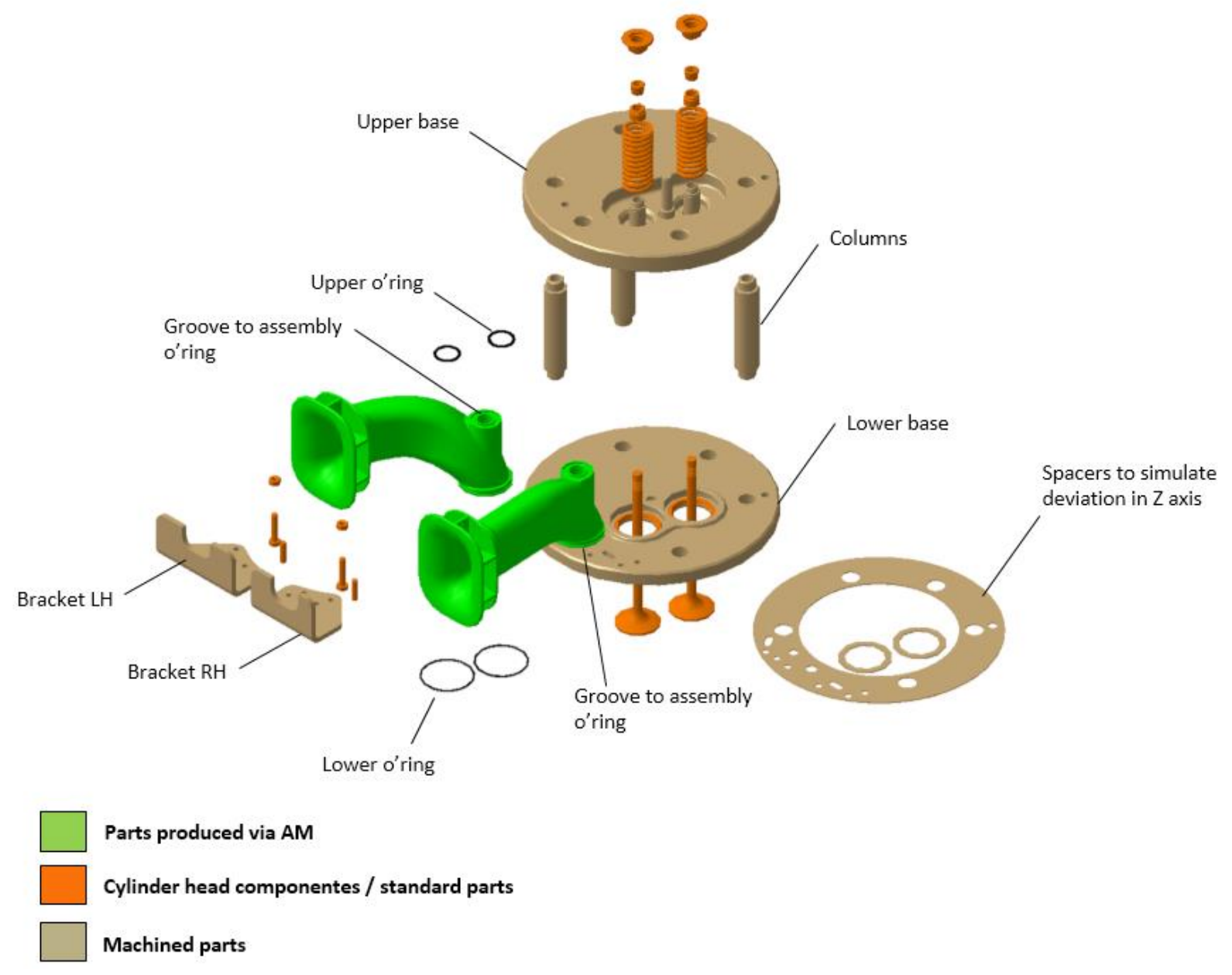

Figure 3 - Modular device design

The modular device was divided in different components to allow the assembly and disassembly for intake ports. Main components function:

- Lower base: provide the necessary mechanical resistance to support the intake valve forces, besides of incorporate the original valve seats and reproduce the complete Model A cylinder head lower face.

- Bracket RH and LH: ensure the intake ports position on modular device.

- Columns: align the lower and upper bases in addition to provide the mechanical resistance while opening and closing intake valves.

- Upper base: provide the necessary mechanical resistance to intake valve spring loads forces, besides of incorporating the valve guides and guide pin to ensure the two valves will open at the same time while performing the data acquisition.

- O-rings: assure no air leakage between intake ports produced via AM and machined interface components. 


\section{ROUGHNESS MEASUREMENT}

Casting components roughness depends upon the method chosen to produce the part, it can

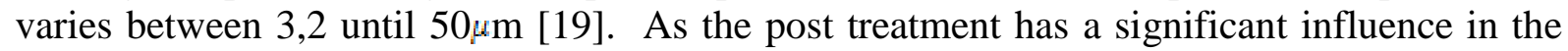
parts produced via 3D printing [20], it was performed the following experiments:

- Experiment A: minimum as possible post treatment in the printed intake ports (Fig.4a).

- Experiment B: maximum as possible post treatment in the printed intake ports (Fig.4b).

In both experiments, the amount of reagent and chemical substance with epoxy base followed 3D printer's manufacturer equipment recommendations.

The equipment used to verify the samples roughness is a 2D profile measurement Taylor Hobson (Fig4c).

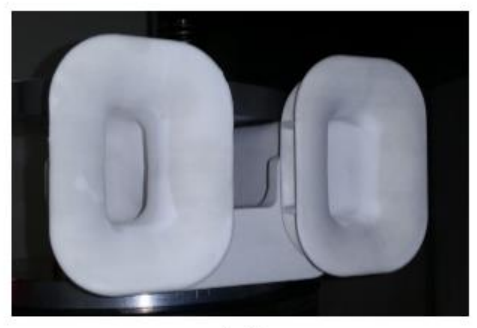

(a)

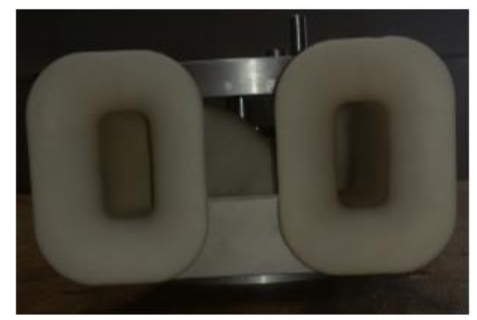

(b)

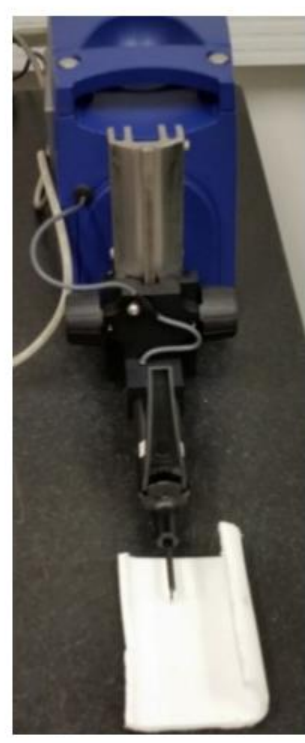

(c)

Figure 4 -Intake ports prototypes measured in the LFS [21]

It was performed four measurements in each sample section, being two longitudinal in the opposite way from the airflow and two measurements in the transversal direction of the intake sample. Results can be seen at table 1:

Table 1 - Average roughness found in the intake ports produced via 3D printing (in $\mu \mathrm{m}$ ):

\begin{tabular}{c|c|c}
\hline & Experiment A & Experiment B \\
\hline Ra (max) & 15,4 & 18,2 \\
Ra (min) & 10,0 & 10,2 \\
Ra (average) & 12,8 & 15,2 \\
\hline
\end{tabular}

The average roughness difference between experiments $\mathrm{A}$ and $\mathrm{B}$ is $15,8 \%$, so the selected method post treatment provides parts with roughness inside the range for casting components. 
Aiming to perform a more deep analysis, also one sample for model A cylinder head was sectioned and sent to the LFS to compare the roughness results:

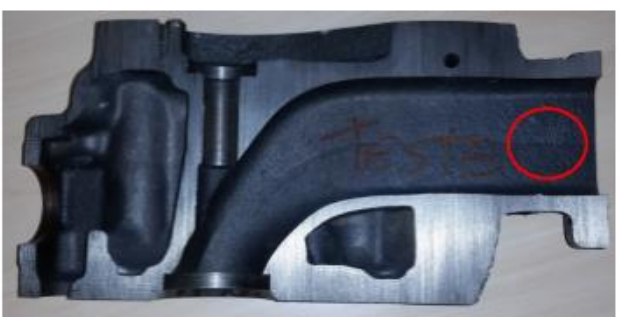

(a)

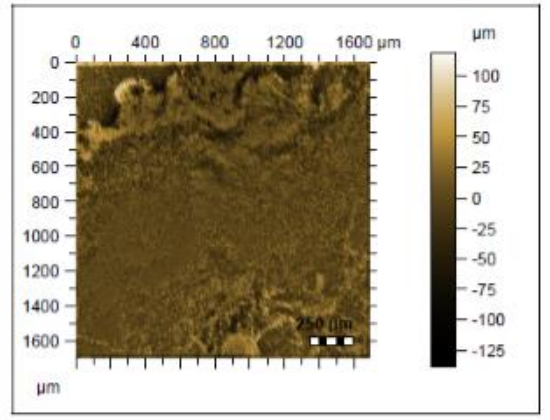

(c)

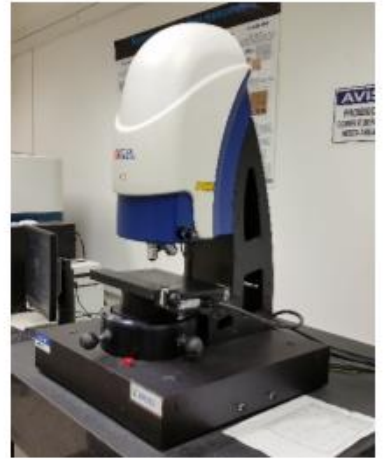

(b)

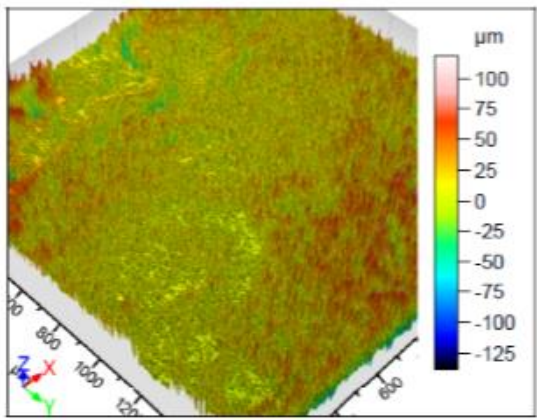

(d)

Figure 5 - Sample and equipment used for roughness measurement in the LFS [21]

In the picture $5 \mathrm{a}$ the area measured is highlighted in red, the cylinder intake port roughness was measured with the equipment CCI MP [22] showed on figure 5b. In 5c and 5d are respectively the topography top view and $3 \mathrm{D}$ view.

Model A cylinder head has $17,3 \mu \mathrm{m}$ of Ra, close values to the ones found in experiments $\mathrm{A}$ and $\mathrm{B}$.

\section{CYLINDER HEAD DATA ACQUISITION}

All data provided in this paper were extracted from [23]. Tests results presented in this paper used the same equipment (Cussons P7300) and the EPUSP laboratory kept the same temperature and humidity control.

One model A complete cylinder head sample was tested 40 times in-cylinder flow rig, the total amount of tests was divided in 4 days. This cylinder head sample is called XY.

In adherence tests, the hypotheses refers to the population distribution [24]. It was applied the Kolmogorov-Smirmov method to verify the test results distribution. 
Since the results have a normal distribution, it was then adopted the average and standard deviation to express them.

The data swirl number results, separated per day are available in the table 2:

Table 2 - Results for XY sample of model A complete cylinder head

\begin{tabular}{c|c|c|c|c}
\hline & $\begin{array}{c}\text { 1st day - } \\
\text { Swirl number }\end{array}$ & $\begin{array}{c}\text { 2nd day - } \\
\text { Swirl number }\end{array}$ & $\begin{array}{c}\text { 3rd day - } \\
\text { Swirl number }\end{array}$ & $\begin{array}{c}\text { 4th day - } \\
\text { Swirl number }\end{array}$ \\
\hline test 1 & 2,109 & 2,094 & 2,057 & 2,094 \\
test 2 & 2,105 & 2,104 & 2,093 & 2,063 \\
test 3 & 2,087 & 2,105 & 2,074 & 2,064 \\
test 4 & 2,112 & 2,099 & 2,055 & 2,058 \\
test 5 & 2,101 & 2,094 & 2,080 & 2,060 \\
test 6 & 2,079 & 2,099 & 2,075 & 2,081 \\
test 7 & 2,106 & 2,091 & 2,056 & 2,046 \\
test 8 & 2,089 & 2,093 & 2,071 & 2,047 \\
test 9 & 2,086 & 2,095 & 2,070 & 2,059 \\
test 10 & 2,078 & 2,098 & 2,059 & 2,034 \\
average & 2,095 & 2,097 & 2,069 & 2,061 \\
max & 2,112 & 2,105 & 2,093 & 2,094 \\
min & 2,078 & 2,091 & 2,055 & 2,034 \\
delta & 0,033 & 0,014 & 0,039 & 0,060 \\
& & & & \\
standard & \multirow{2}{*}{0,012} & 0,005 & 0,013 & 0,016 \\
deviation & \multirow{2}{*}{0,008} & 0,003 & 0,013 & 0,013 \\
95\% C.I. & \multicolumn{3}{|l}{}
\end{tabular}

Global swirl number

\begin{tabular}{c|c|c}
\hline Average & $\begin{array}{c}\text { Standard } \\
\text { deviation } \\
2,081\end{array}$ & $\mathbf{9 5 \%}$ C.I. \\
\hline
\end{tabular}

The biggest swirl number variation occurred in the 4th day of tests, where was found 3\% difference between the maximum and minimum value.

Moreover, as all tests were performed at the same rig equipment and with the same cylinder head sample, it is possible to affirm that the in-cylinder flow rig used for swirl measurements has 0,02 of standard deviation. 


\section{INTAKE PORTS PRODUCED VIA AM DATA ACQUISITION}

After the data acquisition, the XY cylinder head sample was digitalized. The goal of this process is to ensure that $3 \mathrm{D}$ printed intake ports would keep the same internal geometry as complete cylinder head.

Digitalization process can be seen of figure 6:
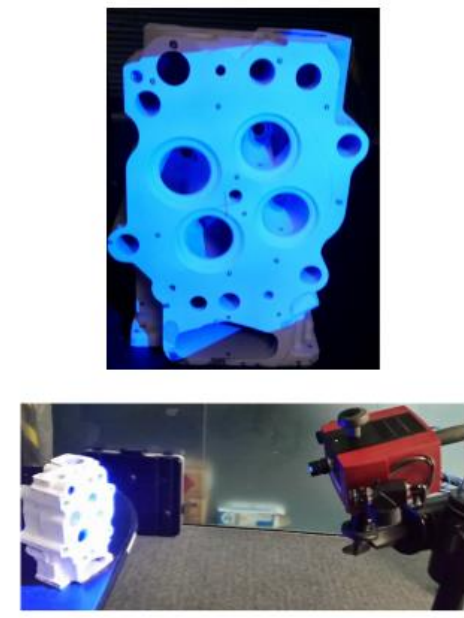

(a)
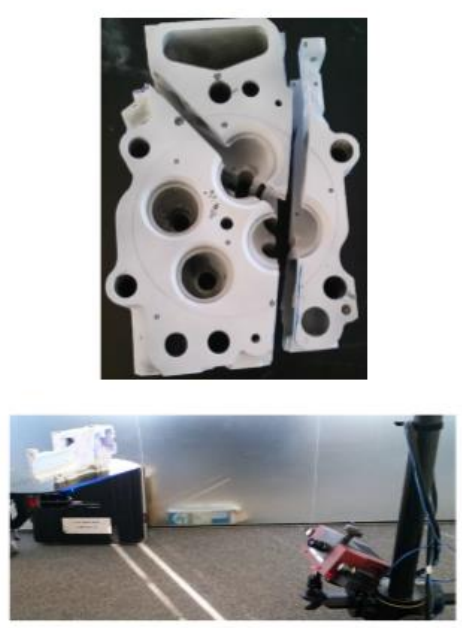

(b)

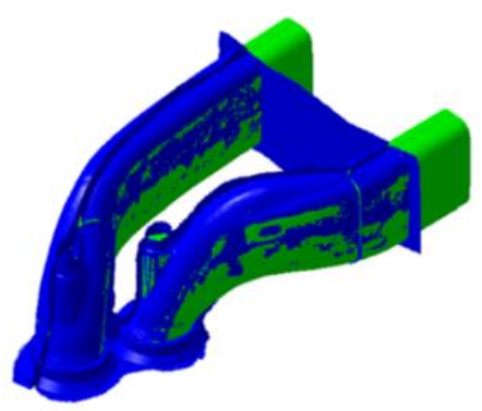

(c)

Figure 6 - Digitalization process

The targets were added into cylinder head and it was scanned prior to section the component (fig. 6a), in this way the equipment kept all references needed to ensure $0.005 \mathrm{~mm}$ accuracy after scan the internal geometry of sectioned cylinder head (fig. 6b).

Once completed the digitalization process, the point clouds was imported to the CAD environment and internal geometry of XY cylinder head sample was reproduced into modular design components (fig. 6c).

The next step was calculate the size of the sample needed. It was done using the expression [24]:

$$
n=\left(\frac{Z_{\alpha / 2} \sigma}{e_{0}}\right)^{2}
$$

Where

$Z_{\alpha / 2}=$ critical value

$\sigma=$ standard deviation

$e_{0}=$ semi-range of confidence interval 
It was used 0.02 for standard deviation $(\sigma)$, which is the value found during the cylinder head data acquisition. Defining $0.02\left(e_{0}\right)$ as desirable precision and $95 \%$ of confidence $\left(Z_{\alpha / 2}=Z_{2.5 \%}=1.96\right)$, it would be needed four elements to estimate the population average. It was decided to build five pairs of intake ports and realize 40 tests due to time disposal.

The five intake ports pairs were printed separately, the goal was to include in the analysis the $3 \mathrm{D}$ printing process variation and then validate the obtained results statically.

All intake ports from this paper were produced by the equipment 3D Systems Project 360 [25]. 3D printed parts used for data acquisition can be seen at figure 7 :

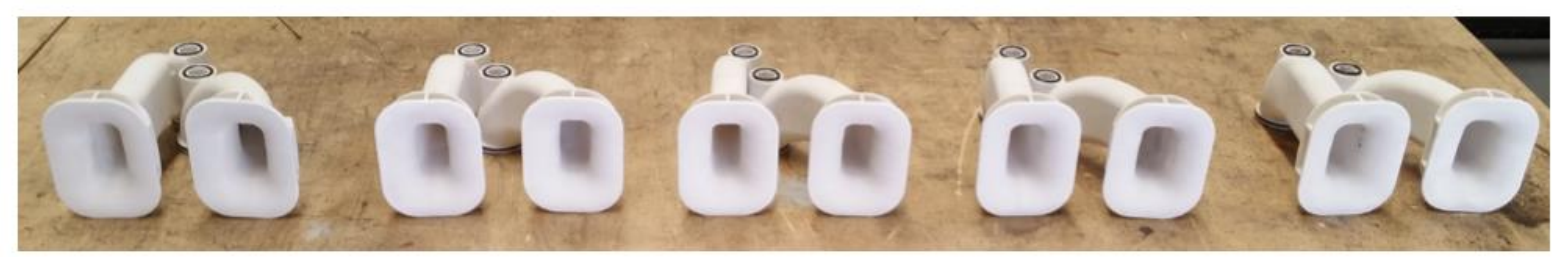

(a)
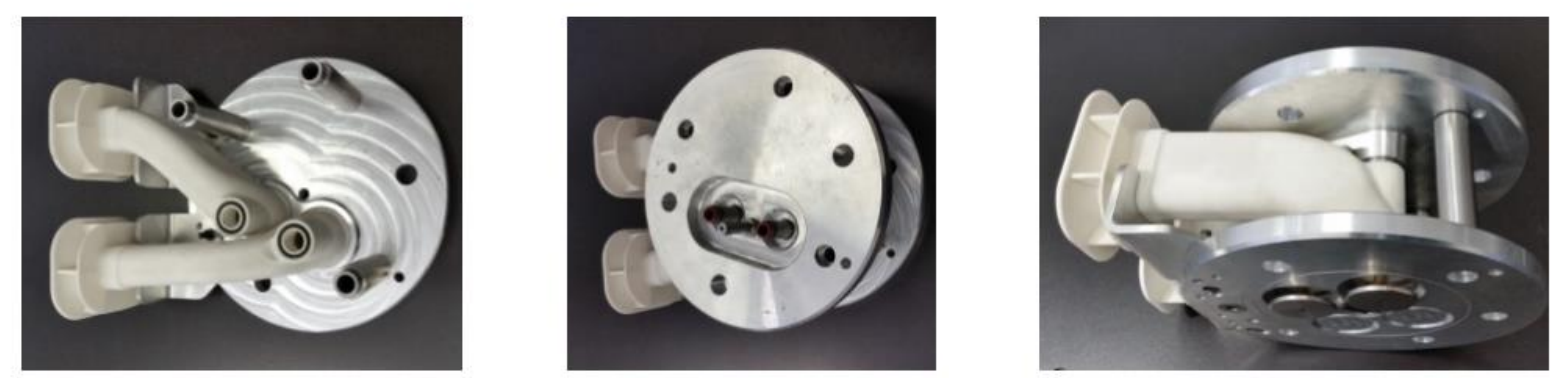

(b)

Figure 7 - intake ports used for data acquisition (a) and modular device prototype (b)

Due to a technical issue, it was only possible to perform 38 tests in the 3D printing intake ports, because the pair\#4 was damaged in the last day of data acquisition.

It was applied the Kolmogorov-Smirmov method to verify the test results distribution. Since the results have a normal distribution, it was then adopted the average and standard deviation to express them.

The data swirl number results, separated per 3D printed intake ports pairs, and are available in the table 3: 
Table 3 - Results for intake ports' AM using same internal geometry as XY cylinder head sample

\begin{tabular}{c|c|c|c|c|c}
\hline & $\begin{array}{c}\text { Pair\#1 - } \\
\text { Swirl number }\end{array}$ & $\begin{array}{c}\text { Pair\#2 - } \\
\text { Swirl number }\end{array}$ & $\begin{array}{c}\text { Pair\#3 - } \\
\text { Swirl number }\end{array}$ & $\begin{array}{c}\text { Pair\#4 - } \\
\text { Swirl number }\end{array}$ & $\begin{array}{c}\text { Pair\#5 - } \\
\text { Swirl number }\end{array}$ \\
\hline test 1 & 2,048 & 2,087 & 2,102 & 2,109 & 2,090 \\
test 2 & 2,039 & 2,083 & 2,095 & 2,091 & 2,076 \\
test 3 & 2,035 & 2,088 & 2,091 & 2,095 & 2,065 \\
test 4 & 2,026 & 2,078 & 2,106 & 2,104 & 2,061 \\
test 5 & 2,081 & 2,110 & 2,062 & 2,147 & 2,144 \\
test 6 & 2,072 & 2,114 & 2,073 & 2,141 & 2,125 \\
test 7 & 2,065 & 2,116 & 2,087 & - & 2,080 \\
test 8 & 2,055 & 2,108 & 2,081 & - & 2,093 \\
average & 2,052 & 2,098 & 2,087 & 2,115 & 2,092 \\
max & 2,081 & 2,116 & 2,106 & 2,147 & 2,144 \\
min & 2,026 & 2,078 & 2,062 & 2,091 & 2,061 \\
delta & 0,055 & 0,038 & 0,044 & 0,056 & 0,083 \\
& & & & & \\
standard & 0,019 & 0,015 & 0,015 & 0,024 & 0,029 \\
deviation & & & & & 0,019 \\
95\% C.I. & 0,013 & 0,011 & 0,014 & 020 \\
\hline
\end{tabular}

\section{Global swirl number}

\begin{tabular}{c|c|c}
\hline Average & $\begin{array}{c}\text { Standard } \\
\text { deviation } \\
2,087\end{array}$ & $\mathbf{9 5 \%}$ C.I. \\
\hline
\end{tabular}

The biggest swirl number variation occurred between pair\#1 and pair\#2, where between the maximum and minimum measured swirl number was found a difference $5.6 \%$.

Even though manufacturing the five pairs separately, with natural deviation from manufacturing process, the proposed method presented a 0.028 of standard deviation at the end of 38 tests.

\section{DATA ANALYSIS}

Deviations up to $+/-2$ N.mm may be a consequence of the measurement equipment accuracy, what would explain the swirl number differences between the cylinder head and modular design in the $3 \mathrm{~mm}-10 \mathrm{~mm}$ valve lift range. It can be seem at figure 8 : 


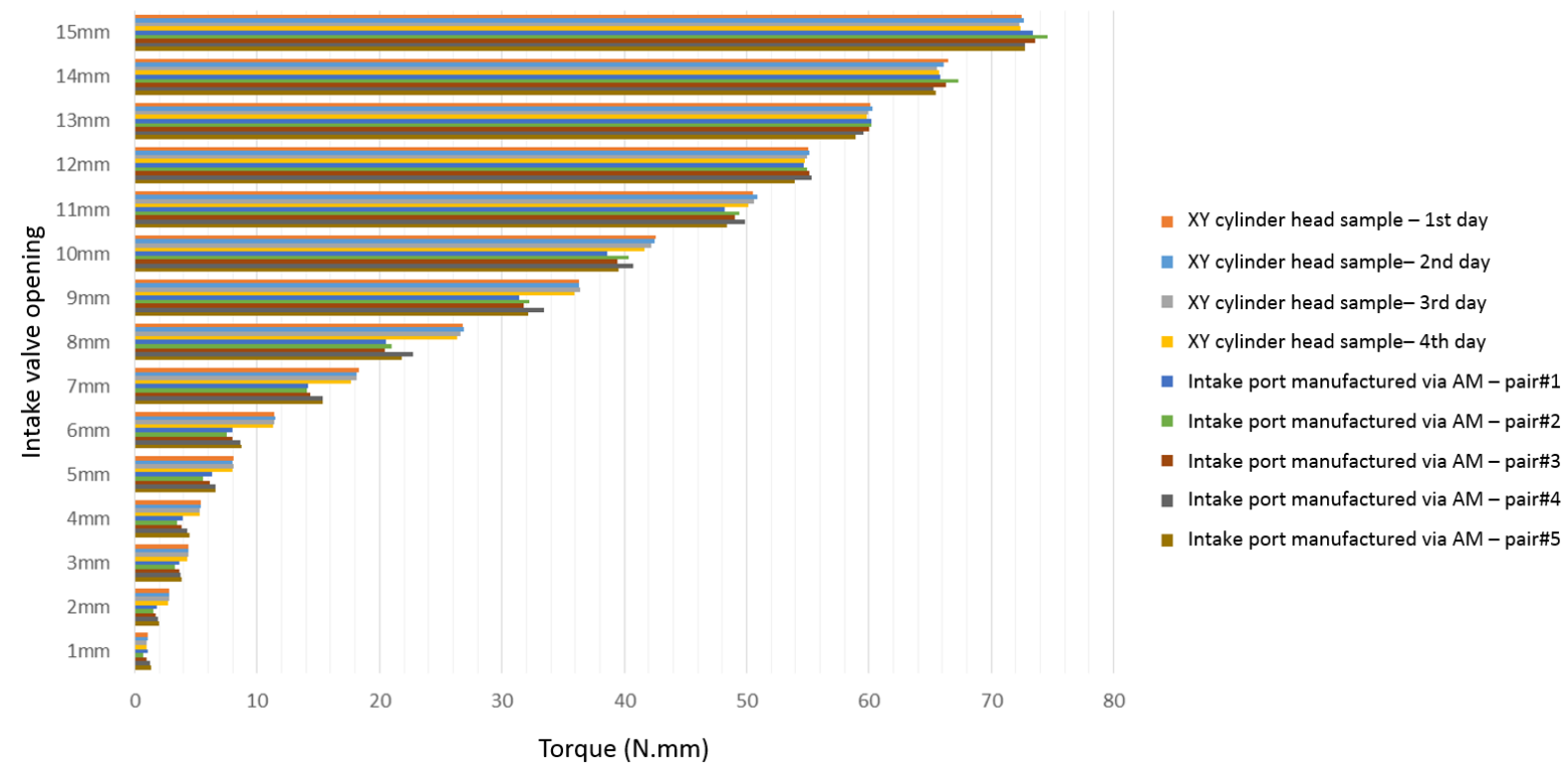

Figure 8 - Torque vs. valve intake valve opening (cylinder head and AM)

At figure 9, a comparison between the average results of torque as function of intake valve opening for the XY cylinder head sample and intake ports manufactured via AM with same geometry is performed.

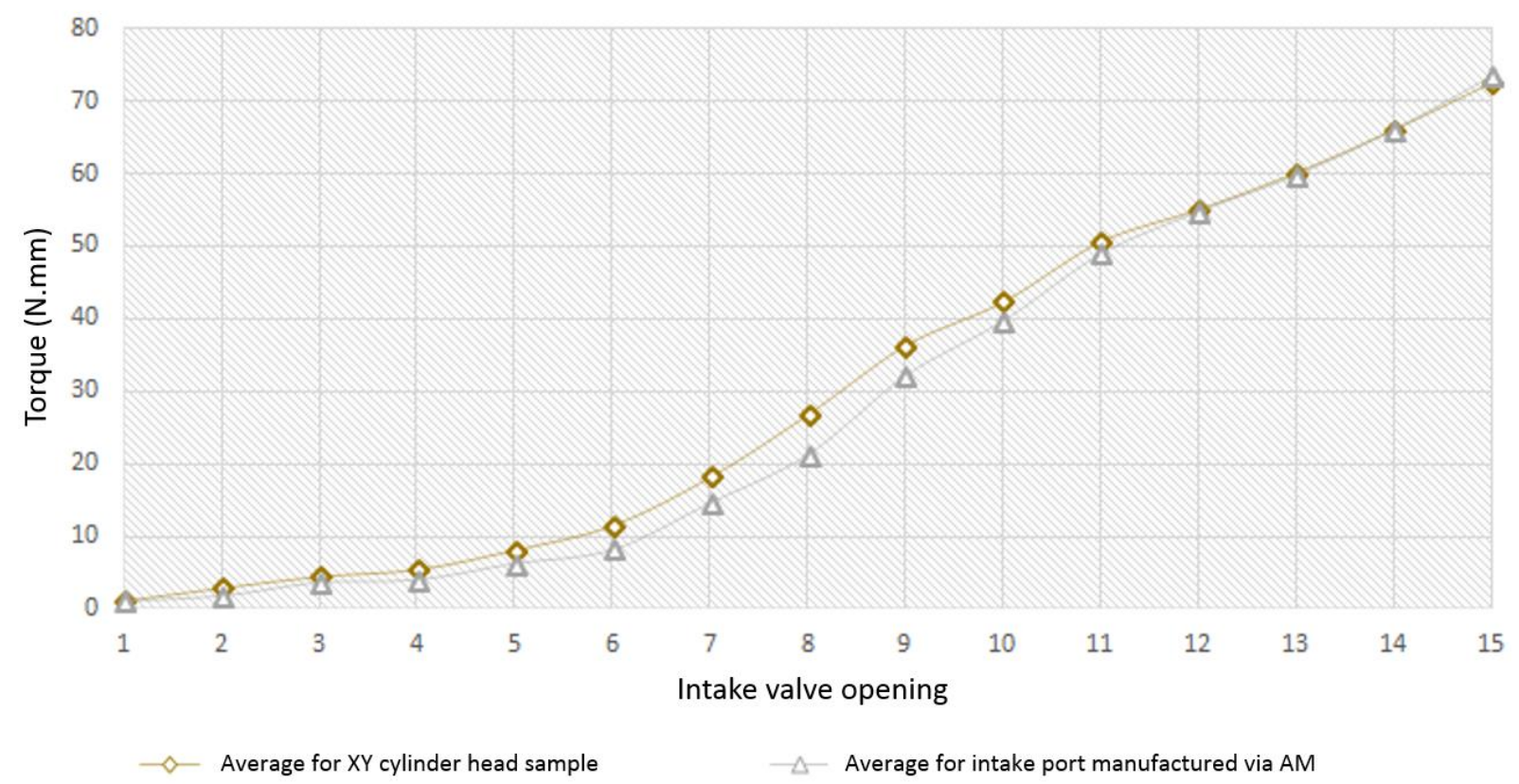

Figure 9 - Torque vs. valve intake valve opening (global tests average)

Considering the measured torque deviations found between $4 \mathrm{~mm}-12 \mathrm{~mm}$ intake valve opening, it was found a torque average difference of 2.6 N.mm or $15 \%$.

All deviations, with the exception of $8 \mathrm{~mm}$ intake valve opening, lies into measurement equipment precision, which is 4 N.mm $(+/-2$ N.mm). For $8 \mathrm{~mm}$ intake valve opening, was 
found a difference of $20 \%$ between cylinder head sample and tested AM intake port (5.4 N.mm).

The swirl tests results summary can be found at table 4:

Table 4 - Results summary

\begin{tabular}{c|c|c|c}
\hline \multicolumn{4}{c}{ Global swirl number } \\
\hline & Average & $\begin{array}{c}\text { Standard } \\
\text { deviation }\end{array}$ & $\mathbf{9 5 \%}$ C.I. \\
\hline XY cylinder head sample & 2,081 & 0,020 & 0,006 \\
Intake ports produced via AM & 2,087 & 0,028 & 0,009 \\
\hline
\end{tabular}

Performing the average test comparison (one sample test $\mathrm{T}$ ), it was observed no statically significant differences in the swirl number results. Statistical analysis results:

- Swirl number (2.081)

$\circ$ Average difference $=0.0064$

- $95 \%$ C.I. of the difference

- Upper bound $=0.01575$

- Lower bound $=-0.00285$

To perform the statically analysis of the results, the data obtained from 38 tests using intake ports manufactured via AM was compared with the swirl number average of XY cylinder head sample.

Proposed method of testing intake ports manufactured via AM, 3D printing, in the case of this paper, is capable to represent the air intake flow in rig measurements. The data acquisition equipment accuracy and manufacturing process precision for the five pairs did not generate any statistically significant differences in the swirl number.

For the interpretation and analysis of statics data was used the software SPSS 20.0 (Statistical Package for the Social Sciences) [26].

\section{CONCLUSIONS}

This paper presents a modular device tool that can be used to perform in-cylinder flow measurements. No statistically significant differences found when the results obtained in the tests with the intake ports manufactured via 3D printing were compared with the cylinder head sample that was digitalized.

Statistical analysis showed a quite small average difference, 0.0064 , between measured swirl numbers of the XY cylinder head sample and the proposed device. Consequently, it is possible to replace, as intended, the complete cylinder head by a modular device using intake ports produced via AM. 
The achieved results are satisfactory, as the swirl number tolerance specified by engine manufacturer is $10 \%$ for nominal values $(+/-5 \%)$ [8 - 9].

Geometry, position and machining deviations can be verified with the intake ports produced via $\mathrm{AM}$ and tested in-cylinder flow rig with the proposed device, such deviations are important to comprehend the swirl deviation trend as function of potential errors from manufacturing process. This investigation is a powerful tool to proper define the manufacturing tolerances.

Product engineering and engine researchers are able to perform a DOE (Design of Experiment) of most relevant cases identified during virtual assessments with the proposed device and, in this way evaluate the boundary conditions adopted in virtual simulation.

Although verified in the EPUSP laboratory, the deviations of intake ports rotation and translation in Z-axis, it was not added in this paper due to not being the goal of this study.

\section{ACKNOWLEDGEMENTS}

Scania Latin America for the project support and provided resources.

\section{DEFINITIONS / ABREVIATIONS}

$\begin{array}{ll}\text { 3D } & \text { Three-dimensional } \\ \text { AM } & \text { Additive Manufacturing } \\ \text { CAD } & \text { Computer Aided Design } \\ \text { EPUSP } & \text { Polytechnic School of Sao Paulo } \\ \text { IEA } & \text { International Energy Agency } \\ \text { LFS } & \text { Surface Phenomena Laboratory }\end{array}$

\section{REFERENCES}

[1] INTERNATIONAL ENERGY AGENCY. Excerpt from CO2 emissions from fuel combustion. 2016

[2] DE STEFANO, M. C.; MONTES-SANCHO, M. J.; BUSCH, T.,A natural resourcebased view of climate change: Innovation challenges in the automobile industry. Journal of Cleaner Production v.139, p. 1436-1448, 2016

[3] SÖDER, M., Creation and destruction of in-cylinder flows; Large eddy simulations of the intake and the compression strokes. 2015. Thesis (Doctoral) - Mechanical Engineering, KTH Royal Institute of Technology, Stockholm

[4] BRUNETTI, F. Motores de Combustão Interna. Vol. 1. São Paulo: Blucher, 2012.

[5] HEYWOOD, J. B. Internal Combustion Engine Fundamentals. McGraw-Hill, 1988. 
[6] PULKRABEK, W. W. Engineering fundamentals of the internal combustion engine. Prentice Hall - Upper Saddle River, 1997.

[7] VANHAELST, R.; CZAJKA, J. Development of an optical sensor for determination of swirl level in diesel engines.2nd Conference on Engine Processes Proceedings, Jul/2015, Berlin

[8] CASTILLA, A.; FERNÁNDEZ, J.; MONTANERO, J.M. Influence of the manufacturing process tolerance on the swirl number of a low-capacity engine. Journal of Manufacturing Systems, v. 41, p. 157-164, 2016

[9] LU, Z.; WANG, T.; LIU, S.; LIN, Z.;HAN, Y. Experimental and modeling study of the effect of manufacturing deviations on the flow characteristics of tangential intake port in a diesel engine. Journal of Engineering for Gas Turbines and Power 2014, v.136/112101

[10] ASTM. ASTM F2792-10 standard terminology for additive manufacturing technologies

[11] GUO, N.; LEU, M.C. Additive manufacturing: technology, applications and research needs. Front. Mech. Eng. 8(3): 215-243, 2013

[12] BOGUE, R. 3D printing: the dawn of a new era in manufacturing? Assembly Automation, Vol. 33 Iss 4 pp. 307 -311, 2013.

[13] GÜNTHER, D. et al. Continuous 3D-printing for additive manufacturing. Rapid Prototyping Journal, Vol. 20 Iss 4 pp. 320 - 327, 2014

[14] PITCHER, G. et.al. LDA and PIV Analysis and Comparison of In-Cylinder Flow Structures under Steady Flow Conditions. $15^{\text {th }}$ Int. Symp on Application of Laser Techniques to Fluid Mechanics, Lisbon, 2010.

[15] FERGUSON, C.R.; KIRKPATRICK, A.T., Internal combustion engines: applied thermodynamics. John Wiley \& Sons, Inc., 2001

[16] PASTOR, J.V.; MARGOT, X.; GIL, A.; DONAYRE, J.C. A methodology to estimate the swirl number at TDC in DI diesel engines: through the combination of CFD and steady flow rig results. SAE Technical Paper 2004-01-1876, 2004.

[17] STONE, C. R.; LADOMMATOS. The Measurement and Analysis of Swirl in Steady Flow. SAE paper No. 921642, 1992

[18] FORTE, C. et. al. Numerical Evaluation of the Applicability of Steady Test Bench Swirl Ratios to Diesel Engine Dynamic Conditions. 69th Conference of the Italian Thermal Engineering Association, ATI 2014

[19] SWIFT, K. G.; BOOKER, J. D. Process Selection: from design to manufacture. 2 ed. Oxford: Butterworth-Heinemann, 2003

[20] GALETA, T.; ŠIMUNOVIĆ, G.; MAZUREK, M. Impact of strengthening fluids on roughness of 3D printed models. Metallurgy, v. 54, p. 231-234, 2015

[21] LFS. Available in: 〈http://www.lfs.usp.br/>. Last access: 2017/05/24

[22] CCI-MP. Available in: <http://www.taylor-hobson.com/products/23/109.html\#CCIMP>. Last access: 2017/05/24

[23] MARTIOLI, G. F. Medição do número de swirl utilizando dutos de admissão do cabeçote de um motor diesel produzidos via prototipagem rápida. 2017. Dissertation 
(Master's degree) - Mechanical Engineering: Automotive Engineering Centre, EPUSP, Sao Paulo.

[24] COSTA NETO, P. L. O. Estatística, 2 ed. São Paulo: Edgard Blücher, 2002

[25] Available in: <http://www.3dsystems.com/3d-printers/professional/projet-360>. Last access: 2017/05/24

[26] IBM Corp. Released 2011. IBM SPSS Statistics for Windows, Version 20.0. Armonk, Nova Iorque: IBM Corp. 